\title{
HANNAH ARENDT E O MALOGRO DO ESPÍRITO REVOLUCIONÁRIO
}

\author{
Odílio Alves Aguiar* \\ Universidade Federal do Ceará \\ (D) https://orcid.org/0000-0002-7767-1932
}

\section{RESUMO:}

O texto examina o conceito arendtiano de revolução presente na obra Sobre a Revolução (1963), focalizando, especialmente, a questão do malogro do espírito revolucionário. Nossa leitura guia-se pela hipótese de que a relação entre a necessidade e a liberdade atravessa a obra da autora e ilumina a compreensão arendtiana de revolução. A opção pela necessidade, pelo econômico, por um lado, e pela formalidade jurídica, por outro, em detrimento da liberdade, está na origem, segundo Hannah Arendt, do malogro do espírito revolucionário no mundo ocidental, particularmente nas suas grandes revoluções: a francesa e a americana.

PALAVRAS-CHAVE: Revolução; Malogro; Necessidade; Liberdade.

\section{HANNAH ARENDT AND THE FAILURE OF THE REVOLUTIONARY SPIRIT}

\begin{abstract}
:
This text aims at examining the concept of revolution present in Hannah Arendt's book On Revolution (1963). It is purported to address more specifically the failure of the revolutionary spirit. The hypothesis presented here is the following: the understanding of the relations between necessity and freedom outlined by Arendt in On Revolution shows that the failure of the western revolutionary spirit is rooted in the fact that it favored economy and necessity on the one hand and juridical formalism on the other, but to the detriment of freedom. Arendt saw this happening both in French and American revolutions.
\end{abstract}

KEYWORDS: Revolution; Failure; Necessity; Freedom.

Examinar o livro Sobre a Revolução (1963), de Hannah Arendt, é entrecruzar texto e história; é propor, de alguma forma, uma hermenêutica

\footnotetext{
* Doutor em filosofia e professor da Universidade Federal do Ceará (UFC), Ceará - Brasil. E-mail: odilio@ufc.com.br
} 
"do que estamos fazendo". Nessa linha, entendemos que a atual situação política mundial e nacional aponta a urgência da reavaliação do conceito de revolução. Na compreensão arendtiana da revolução, na obra em pauta, chama atenção a questão do malogro revolucionário. Esse malogro relaciona-se a uma perspectiva que atravessa toda a obra de nossa autora, do início ao fim: dos escritos judaicos iniciais aos assuntos d'A Vida do Espírito (1976). Referimo-nos à relação e diferenciação entre as categorias da necessidade e da liberdade e suas implicações políticas. Isso não está relacionado apenas à importância da economia no mundo moderno, mas aos perigos da renúncia à fundação de espaços de organização, participação e convivência humana na modernidade.

Essa atitude foi muito bem assinalada por Giorgio Agamben, em suas teses sobre a biopolítica esboçadas em Homo Sacer I (AGAMBEN, 2002), embora Arendt não comungue com o pessimismo de Agamben, posto que nossa autora mantém sua aposta na ação e no julgamento. $O$ que retemos é o encaminhamento biopolítico que acarretou o sacrifício da dimensão de fundação política da sociedade. Resíduos e traços da pretensão político-fundacional mantém-se vivos e são eles que fortalecem a resistência à tendência sacrificial hegemônica das atuais práticas políticas, econômicas e sociais biopolíticas. Na tendência sacrificial, a descartabilidade humana, o mal radical, não é fruto apenas da escassez econômica superável com o progresso. Ela é elaborada através de meandros provenientes da ciência e da tecnologia (a eugenia biotecnológica, a virtualização e a passividade da existência humana, a guerra tecnológica), da economia (padrões de consumo), da sociedade (padrões de beleza e moda) e da cultura transformada em entretenimento, domesticação e profissionalização.

A relação entre a não fundação política e a descartabilidade humana foi muito cedo percebida por Arendt; era isso que motivava seu embate com a visão assimilacionista da questão judaica. A supremacia da postura assimilacionista, economicista, entre os judeus, e a incompreensão da dimensão política da questão judaica aparecem e são criticadas desde os primeiros textos de Hannah Arendt. É esse o teor que extraímos quando ela afirma que a postura assimilacionista e filantrópica do judaísmo foi o atalho que levou direto aos campos de concentração. Essa ligação entre assimilacionismo e holocausto faz-se presente em vários textos sobre a questão judaica anteriores e posteriores a Origens do totalitarismo ${ }^{l}$. Vale dizer, sem a rede político-institucional, a vida humana fica desprotegida. Investir na garantia da reprodução biológica, econômica, descuidando da proteção político-participativa, pode até facilitar a resolução sacrificial que se efetuou nos campos de extermínio. A compreensão da segurança e da proteção como filantropia foi a saída que a modernidade ofereceu ao judeu

\footnotetext{
${ }^{1}$ Vale mencionar, a esse respeito, as coletâneas que saíram na França: La tradition cachée Le Juif comme paria. Paris: Christian Bourgois, 1987 e Auschwitz et Jérusalem. Paris: Deux temps, 1991.
} 
e, ao invés de levar à emancipação, levou ao antissemitismo e às câmaras de gás. O antissemitismo moderno, segundo Arendt, é contemporâneo do assimilacionismo. Contra essa perspectiva, Arendt rebelou-se no artigo "L'Aufklarung et La question juive" (1932) e a estendeu ao humanitarismo a crítica aos direitos humanos em Origens do Totalitarismo (1951). Sem pertencer a uma comunidade política, a humanidade dos homens corre perigo. Movimentamos-nos, assim, no âmbito de uma consideração do pensamento arendtiano, na linha proposta por Richard Bernstein, na obra Hannah Arendt and the Jewish Question, na qual, a questão judaica (die Judenfrage) é o ponto de partida da sua reflexão (BERNSTEIN, 1996. p. $\mathrm{X})$. Essa perspectiva é asseverada pela própria Arendt numa carta a Jaspers: "Eu tenho recusado abandonar a questão judaica como o ponto focal do meu pensamento histórico e político." (ARENDT; JASPERS, 1992, p. 31).

Após a escrita de Origens do totalitarismo, em 1951, a estreiteza na compreensão assimilacionista dos problemas judaicos, entre os judeus, torna-se fulcral para o entendimento do mundo moderno. Podemos observar esse posicionamento no texto "Karl Marx and the tradition of Western Political Thought", no qual Arendt afirma que na modernidade, radicalizando um fio teórico típico da tradição ocidental, a questão central da política passou da liberdade para a necessidade, da convivência para a economia (ARENDT, 2002, p.290). Essa compreensão se fará presente, de alguma forma, em todas as suas obras posteriores, de forma mais explícita, em A Condição Humana (1958) e Entre o Passado e o Futuro (1961); ou menos explícita, em Homens em tempos sombrios (1968) e A Vida do Espírito (1976).

Em Sobre a Revolução, também verificamos a potência heurística do par conceitual necessidade-liberdade em movimento. Evidentemente a tematização arendtiana dessas categorias não se vincula às clássicas elucubrações metafísicas presentes na história da filosofia sobre esse assunto. $\mathrm{O}$ modus operandi de Arendt aciona a perspectiva compreensiva e dialogadora com as experiências históricas e políticas concretas; e capta, como escreveu André Duarte (2013), a "paradoxal combinação ou correlação entre opostos" presentes nos acontecimentos, exigindo a colocação desses termos, como os demais pares opostos presentes na sua obra, no horizonte do "movimento geral de seu pensamento sem ater-se simplesmente a certos enunciados particulares [...], sem comprometer a totalidade de seu pensamento com formulações rígidas." (DUARTE, 2013, p. 39-62).

Nossa leitura pode ser, assim, uma oportunidade interessante para confrontar algumas tendências que surgiram nas leituras da obra de Arendt e que são excessivamente reducionistas do seu pensamento. A principal característica da metodologia arendtiana reside em sua capacidade de distinguir e relacionar conceitos. 


\begin{abstract}
Esta interpretação opõe-se às leituras que enfatizam o caráter rígido e dicotômico das distinções arendtianas, aspecto que as tornariam inviáveis para a discussão de problemas políticos contemporâneos. Com relação a essas críticas, [...], frente à ruptura da tradição, Arendt exercita um pensamento 'sem amparos', nem dialético nem esquemático, mas que simultaneamente distingue e relaciona conceitos opostos, tornando-os inteligíveis por meio de sua confrontação e complementaridade (DUARTE, 2013, p. 39).
\end{abstract}

O tópico liberdade-necessidade emerge em Arendt inerentemente vinculado aos assuntos históricos e, no caso em pauta, àqueles que compuseram os fenômenos revolucionários modernos. Esses fenômenos serão observados através da tentativa arendtiana de compreender o malogro do espírito revolucionário. No texto arendtiano, nas entrelinhas e, às vezes, explicitamente, salta aos olhos a pergunta sobre o fracasso das revoluções. Ambos os modelos revolucionários fracassaram. Embora os acontecimentos que levaram a isso tenham sido diferentes, filosoficamente podem ser reunidos na aderência à necessidade em detrimento da liberdade nos dois padrões revolucionários.

Abordar o fracasso revolucionário não significa dizer que Arendt queira negar a importância e até mesmo, paradoxalmente, o sucesso das revoluções modernas e sua presença na contemporaneidade. Ao contrário, para o bem e para o mal, é a forte influência da revolução francesa e da revolução americana no ocidente que leva nossa autora a se debruçar sobre o fenômeno revolucionário moderno. Nosso mundo é fruto dessas revoluções e, por esse lado, elas foram vitoriosas, bem-sucedidas. Esse enfoque paradoxal exigiria uma avaliação das formas sociais e políticas modernas. Assunto para outro debate. Limitamo-nos a apontar alguns aspectos ressaltados por Arendt que nos ajudarão na compreensão do seu ponto de vista sobre o fracasso revolucionário.

Nas interpretações do fenômeno revolucionário, destacam-se, grosso modo, duas visões: a proveniente da compreensão marxiana, presente já em A questão judaica, de 1843, na qual a emancipação política é desdenhada em razão da compreensão formalista e legalista da cidadania no recémfundado mundo burguês. No seu lugar, Marx propõe a revolução social, capaz de gerar a igualdade não entre cidadãos, mas entre os homens ( $\mathrm{Cf}$. MARX, 2010). A libertação dos constrangimentos provenientes da escassez econômica é o único caminho capaz, segundo Marx, de gerar a verdadeira igualdade entre os homens. Nascia, nessa obra, da lavra do jovem Marx, a impaciência em relação aos temas políticos e a aposta na economia como a dimensão ontologicamente capaz de solucionar e romper, uma vez por todas, as correntes da opressão humana geradas pela escassez, cisão social e as necessidades biológicas. Esse foi o motivo da não abordagem da política na obra marxiana e o alto investimento da sua reflexão na compreensão do capitalismo, grande sucesso do seu pensamento. 
A outra visão é justamente a liberal, segundo a qual, o grande fruto da revolução moderna é a liberdade entendida, desta feita, como liberdade individual, patrocinada pelos direitos civis, notadamente a propriedade. Nessa visão, o homem livre é aquele dedicado aos seus negócios e aos seus interesses privados. O homem é livre para realizar empreendimentos econômicos. A iniciativa política é resguardada ao Estado e à sua soberania. Grande patrocinador dessa visão foi os direitos humanos aos quais coube a função de proteger os homens contra a invasão estatal. Embora lutasse contra os privilégios, a visão liberal acabou gerando o retorno da desigualdade ao fazer relação entre liberdade, igualdade e propriedade. Essa perspectiva resvalou para a política na medida em que patrocinou a institucionalização da representação, dos partidos políticos, pois com eles vieram a elitização na política e a impotência dos cidadãos.

Arendt também liga revolução à liberdade. A diferença é a compreensão da íntima pertença da liberdade à política. Nossa autora ressalta que a liberdade é o suprassumo do espírito revolucionário que iniciou e alimentou os processos revolucionários. A febre pela inovação, a vontade de libertação de todas as correias geradoras da opressão, do esquecimento, da desigualdade, o anseio pela distinção, pela participação e a reorganização da convivência tipificam, para Arendt, o espírito revolucionário. Já na apresentação de Sobre a Revolução a ligação entre liberdade e revolução será usada para diferenciá-la da guerra e da revolta ou rebelião. A guerra se faz por conquista de território, riqueza, expansão, defesa de capital investido, manutenção da dominação etc. Por isso, a guerra é um fenômeno antigo e tradicionalmente concebido como ultima ratio e sua marca é o recurso imediato à violência. A revolução, no seu sentido

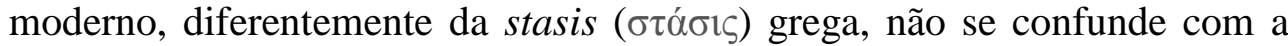
simples revolta de facções, nem mesmo com a metabolé ( $\mu \eta \tau \alpha \beta o \lambda \eta)$, a mudança recorrente nas formas de governo, cuja tendência aos extremos provocava constantemente a mutatio rerum. Não estamos falando mais nem da metabolé $(\mu \eta \tau \alpha \beta o \lambda \eta)$ grega nem da mutatio rerum dos romanos. Algo completamente diferente se faz presente nas revoluções modernas. Elas se realizam dentro de um espírito de ruptura e ressaltam a capacidade de iniciar algo novo, mesmo quando reivindicam uma ligação com acontecimentos gregos ou romanos. A Revolução atrela-se, desse modo, à ideia de novo começo, de natalidade, de nascimento de algo completamente novo.

A especificidade da visão arendtiana da liberdade faz com que permeie em Sobre a Revolução a ideia de que revolução e aparição se coadunam e co-pertencem. (ARENDT, 2011, p. 163). Constituir uma esfera em que os homens não sejam meros animais e possam aparecer uns para os outros como capazes de agir e falar é o leitmotiv inicial de todas as revoluções. As discussões sobre forma de governo, modos de participação, liberdade de expressão, igualdade nas deliberações etc são assuntos que ganharam um peso enorme e estão na essência do espírito revolucionário 
moderno. Essas ideias espalharam-se no ocidente e ainda hoje mobilizam setores enormes da população. A noção de aparição é muito forte em nossa autora e é muitas vezes confundida com mera performance, exibicionismo etc. Talvez por isso ela retome um truísmo aristotélico e relacione política a beleza (Kalon, $\kappa \alpha \lambda o v)$. Diz ela no texto sobre a crise da cultura: "o critério apropriado para julgar aparências é a beleza”. (ARENDT, 2000, p. 263). Beleza, no caso, é a capacidade de fundar e manter instituições, espaços e comunidades capazes de propiciar oportunidades dos homens serem, agirem, aparecerem na sua singularidade e, assim, superarem o mudo pertencimento à espécie natural humana. A revolução trazia essa promessa de as pessoas serem participantes dos governos. Ser digno, igual, livre para falar e agir era o grande compromisso das revoluções, por isso a importância do estabelecimento da esfera de aparição na qual possa se medir a estatura e a dignidade humana. É nessa direção que as promessas revolucionárias apontavam, mas não se cumpriram. Sem o estabelecimento desses espaços de fala e deliberação, o discurso torna-se algo inalcançável, excepcional, prática heróica. O contraponto da aparição é a forma moderna da representação política que veremos mais a frente.

A inerência entre revolução e liberdade provocou a ruptura do conceito tradicional de autoridade e dos privilégios políticos e sociais a ele atrelados. A secularização, a separação entre política e igreja, fortalecida pela reforma, foi fundamental nesse processo de ruptura com a tradição e sua versão da autoridade. Dessa forma, o tesouro revolucionário ("The revolutionary spirit of freedom"), descoberto e acionado pelos revolucionários modernos, trazia no seu interior a ânsia pela liberdade, o espírito público e a consciência da importância de constituição de um novo mundo capaz de preservar esse tesouro. As dificuldades ou equívocos, de diversas ordens, no estabelecimento de uma convivência, de uma nova forma de governo capaz de manter esse espírito revolucionário, levaram ao fracasso, segundo Arendt, as revoluções modernas, tanto as de linhagem francesa quanto americana. Esse fracasso fez-se sentir e aparecer na ponta, na contemporaneidade, na forma do surgimento do terror nazista (remissão ao etnocentrismo prenhe na versão nacional e soberana dos estados modernos), do terror do comunismo soviético (remissão à ditadura do proletariado) e da sociedade de massa e de consumo nos Estados Unidos.

A compreensão desse malogro é importante porque permite questionar a visão de Arendt como defensora da revolução americana em detrimento da francesa: ambas fracassaram. Erram assim Habermas e outros ao afirmarem que para Arendt a revolução americana, política, é a boa e a francesa, social, é a má (Cf. HABERMAS, 1966, p. 479-482; RIBEIRO, 1993. p. 197-119). Outra coisa interessante a se observar é o antielitismo que salta nas posições de Arendt. Isso não é pouco se considerarmos que essa autora é avaliada pela maioria dos seus intérpretes como possuidora de uma concepção elitista da política. 
Quais foram os entraves que dificultaram as revoluções de realizarem e manterem vivo o espírito revolucionário nos dois lados do mundo? Segundo Arendt, as revoluções não conseguiram encontrar a instituição apropriada ao seu espírito. Falharam em levar para o plano constituído, institucional, os elementos constituintes, fundadores; não acolheram, do ponto de vista da forma revolucionária de governar, as tradições e as experiências organizativas que espontaneamente brotaram nas práticas da população apoiadora da revolução. Arendt usa os exemplos da comuna de Paris, das "pequenas repúblicas" e das "repúblicas elementares" que não conseguiram ser abrigadas nem formal nem praticamente (ARENDT, 2011, p. 307-308). Constitucionalmente optou-se pelo poder centralizado, soberano, foram criados e mantidos os partidos e, nessa perspectiva, a tradição centralizadora jacobina obteve a hegemonia na formatação das instituições modernas. Nos Estados Unidos, o mesmo desastre aconteceu. A constituição desconheceu e não acolheu, no pacto federativo, as experiências, já tradicionais na colônia, das assembleias participativas e deliberativas dos municípios e das câmaras municipais, os town-hall meetings, entre outras.

Para Arendt, a revolução não conseguiu manter e colocar em movimento a ligação entre poder constituído e poder constituinte (Cf. ARENDT, 2011, 214-216; PANCERA, 2013, 140-153; QUINTANA, 2013, p. 120-139). Na tradição, essas duas dimensões do poder foram pensadas sem relação. A origem do poder era externa, pré-política e daí provinha a autoridade do governo. A partir das revoluções modernas, temos a promessa de um poder fundado politicamente. A proposta era a geração de uma forma de governo capaz de acolher as iniciativas, a capacidade de agir, de falar e participar dos cidadãos. Para nossa autora, ou se participa do governo ou não se é livre. Dessa forma, as instituições não se separariam nem se encastelariam em si mesmas, nos seus formalismos. No entanto, a concepção moderna de representação, de lei, do progresso humano, favoreceu o legalismo, a massificação, a solidão e a impotência dos cidadãos. Em vez de diminuir, aumentou o espaço e a diferença entre governados e governantes. A naturalização e transcendentalidade do poder, marcas dos antigos regimes, entraram pelas portas do fundo.

A dificuldade de ligar poder constituído a poder constituinte certamente está relacionada à hegemonia da necessidade sobre a liberdade. A centralização e excessiva proteção do poder soberano tornaram-se condição para liberação do fluxo do poder econômico e do livre desenvolvimento da acumulação capitalista. O livre curso do progresso transformou em intransponíveis as duas grandes barreiras que apareceram nas duas revoluções: a questão social, por um lado, e a escravidão, por outro. No lugar da liberdade, surgiu a revolução permanente, o terror jacobino; no lugar da felicidade pública, tomou lugar o sonho americano: a opulência, o consumismo; em ambas, a utópica esperança da superação da 
sisífica condição humana, a utópica liberdade dos grilhões de todas as necessidades. No processo de constitucionalização da revolução, houve a supremacia dos direitos privados e civis sobre os direitos públicos e os antigos privilégios e desigualdades se repuseram. A miséria e o luxo compartilham o mesmo desdém pelo espaço de aparição, segundo Arendt: "as cadeias da necessidade não precisam ser de ferro: podem ser feitas de seda" (ARENDT, 2011, 186). As revoluções, principalmente a francesa, não perceberam a diferença entre libertação (liberation) e liberdade (freedom). A revolução americana aproximou-se da ideia de fundação, mas não acolheu as tradições organizativas que poderiam manter vivo o espírito revolucionário. Para Arendt, as revoluções mostraram-se bem-sucedidas na dimensão de libertação do subjugo monárquico, por um lado, e do domínio colonial, por outro. Mas revolução não é só libertação, é também fundação, constituição de espaços que preservem o espírito que alimentou o élan libertador e revolucionário inicial. Arendt, sobre isso, afirma: "o fim da rebelião é libertação, ao passo que o fim da revolução é a fundação da liberdade." (ARENDT, 2011, p. 189).

Numa linha retrospectiva e judicativa, nossa autora anota que algumas confusões, na compreensão de alguns assuntos, levaram a equívocos e a muitos desastres práticos nos encaminhamentos que visavam criar as novas instituições revolucionárias. Destacamos a confusão entre libertação e liberdade, a dificuldade de relacionar autoridade e igualdade, a indistinção entre geração e legitimidade do poder, a confusão entre questão social e constituição do poder, a imperceptível relação entre massificação e elitização política, as armadilhas da representação política, entre outras.

Libertação diz respeito às lutas que ensejam destravar as relações humanas forjadas na opressão, no privilégio, na tirania etc. Nesse momento, muitas vezes é necessário o uso da violência e da resistência armada, mas isso não pode ser confundido com fundação. Tomada como fim último da revolução, a violência torna-se permanente e apenas multiplica e gera mais violência. A violência pode ser útil para possibilitar a comunidade a se organizar a partir de novos parâmetros, novas promessas consentidas e acordadas publicamente (Cf. ARENDT, 2011, p.64-66). A libertação tem o seu arremate e significação na medida em que forja espaços de aparição, de igualação política, de pertença à comunidade organizada. Sem ativar esse tesouro, nenhuma violência terá consistência. Quanto mais esses espaços de pertenças forem efetivos, decrescerá o desamparo e diminuirá a violência. Se a libertação não levar à liberdade de ação, de expressão, de movimento e de organização, qual o seu sentido? Foi justamente isso que Arendt verificou e questionou nas práticas das tradições revolucionárias. No lado francês, foi implantado o terror, a revolução permanente e criou-se uma tradição que fez sucesso posteriormente, seja na forma de soberania nacional, seja na forma da ditadura revolucionária ou ditadura do proletariado. No lado americano, o não enfrentamento da escravidão limitou 
enormemente a fundação revolucionária e apenas adiou um problema que marcou e gerou profundas lutas e sequelas na comunidade americana e mundial.

O problema maior passa a acontecer quando, ao invés de se direcionar a fundação da liberdade, a política passa a prolongar o leitmotiv da libertação, desta feita, não mais contra a tirania, mas contra a necessidade, a escassez em si. Com isso, a política desaparece como espaço de aparição e transforma-se em mera gestão da economia e dos humanos. Essa opção prevaleceu no ocidente. Antecipando-se a Agamben, em Homo Sacer, Arendt recupera e usa, algumas vezes, em Sobre a Revolução, o termo romano Homo, que se distingue de persona pertencente aos Socii. Esses eram os associados, pactuantes, cidadãos, membros da Civita; aqueles eram meros pertencentes à espécie humana, reduzidos à sua dimensão biológica, mera vida (Cf. ARENDT, p.148-149). O problema não é a revolução ensejar dar condições iguais para todos, isso é defendido por Arendt. Na sua perspectiva, a educação e a tecnologia poderiam resolver, conjugadas com a igualdade e a responsabilidade política, os urgentes problemas provenientes da pobreza e da má distribuição da riqueza. O embaraço aprofunda-se na medida em que a absolutização da questão social passa a compreender a libertação como o utópico desejo humano de ver-se livre, uma vez por todas, das agruras e das recorrentes exigências provenientes das exigências de reprodução biológica. Quando isso ocorreu, a questão social transformou-se numa necessidade histórica, inelutável; o lugar da política foi usurpado e o seu sentido de espaço de aparição, desapareceu. Se isso inicialmente simbolizou a entrada da hipocrisia como um vício público e a piedade como virtude política, logo em seguida significará a assunção do progresso econômico à finalidade última dos investimentos humanos. Uma vez transformada a questão social e o progresso econômico em finalidade última, pouco importará se a convivência humana está estabelecida nos marcos da tirania, da dominação e da violência. A obsessão de superar, uma vez por todas, o problema da escassez, condição dos seres vivos e das suas lutas vitais, acarretou, como muito bem percebeu Arendt, em A Condição Humana, a artificialização completa da vida. $\mathrm{O}$ sonho infinito de alcançar a abundância e não mais a superação das simples carências vitais, acionou o conjunto da inteligência e dos esforços humanos na política, na ciência, na técnica e na economia. O que estamos colhendo, paradoxalmente, é a violência, a tirania, a corrupção, a fome, o crime organizado, como se as antigas pragas retornassem, só que, dessa vez, mediadas pelas mais altas sofisticações provenientes do artifício humano. Com a transformação da vida, através da questão social, no assunto mais importante entre os humanos, o ilimitado, o absoluto e o infinito invadiram as relações humanas; e a vida mesma, sem as proteções provenientes dos frágeis pactos e das promessas políticas, viu-se a mercê 
dos interesses das corporações econômicas, dos tiranos, da manipulação tecnológica e dos grupos poderosos.

Manifestava-se, desta feita, com a entrada e a absolutização da questão social nas revoluções (e depois nas instituições modernas), uma dificuldade de os revolucionários pautarem-se no metro da legitimidade política e liberarem-se da legitimidade absoluta e transcendente para o poder político. Retomavam-se, assim, velhas práticas do antigo regime e das monarquias esclarecidas. A articulação do poder político a uma dimensão excepcional gerou grandes dificuldades para a questão da legitimidade. Essa articulação foi testemunhada pela história do pensamento político e da teoria política. Muitos artifícios e artimanhas teóricas foram criados. As leis naturais, o legislador externo, os dois corpos do rei, o potestas legibus solutos, a exceção soberana, entre outras, são figuras apontadas por Arendt como tentativas de se criar uma estabilidade na política para além dos pactos e promessas mútuas, mas que na verdade favoreceram a tirania, a monarquia, os grupos e etnias poderosas, o Estado etc.

Nesse aspecto, chamam atenção as observações de Arendt a respeito das dificuldades provenientes da nova exigência de ligar legitimidade e igualdade (Cf. ARENDT, 2011, p. 233-235). A tradição vinculava o poder a dimensões pré ou além da política: origem divina, sanguínea ou racional. Isso acontecia sempre como modo de justificar o caráter e a capacidade excepcional do governante agir ou decidir. Acontece que no espírito revolucionário não há mais lugar para esse tipo de coisa. Agora todos são iguais e podem participar e decidir sobre os assuntos comuns. Nessa direção, a legitimidade absoluta, hierarquizante, não se justifica; por outro lado, os dirigentes revolucionários querem apressar a resposta à necessidade e urgência histórica e, deste modo, recorrem ao antigo truísmo da legitimidade absoluta (questão social, soberania nacional), da compreensão religiosa e imperativa da lei.

A solução para essa aporia entre legitimidade, autoridade e igualdade foi resolvida retornando-se à tradicional confusão na compreensão entre origem e legitimidade do poder, poder e autoridade. A lógica e o espírito revolucionário moderno indicavam o povo como origem do poder e a constituição, a "lei maior", como sua legitimidade. Lei aqui pensada como relação ("rapport"), capacidade de vincular, unir e motivar os homens a pertencerem e a participarem da comunidade política (Cf. ARENDT, 2011, p. 233-235). Esse espírito revigora-se nas opiniões dos membros da comunidade e não dos grupos, partidos ou corporações que se manifestam através da opinião pública não política. Assim, a lei e a opinião, expostas e discutidas publicamente, sustentam e dão legitimidade ao poder. A autoridade do poder estriba-se na sua dimensão republicana, isto é, no consentimento popular, nas leis e na opinião politicamente construída. As leis republicanas sancionam promessas mútuas, não tem validade absoluta. 
Nessa linha, autoridade e legitimidade do poder casam com fundação constitucional do corpo político.

Em vez de enveredarem por essa trilha, segundo Arendt, a revolução enveredou pelo formalismo e legalismo e isso significou: primeiro, a desvinculação das leis em relação às práticas e aos pactos da comunidade politicamente organizada e, desse modo, fragilizavam a política moderna e amorteciam o espírito revolucionário nas constituições modernas; segundo, a retomada de um conceito religioso, imperativo de lei que não acolhe as exigências e consentimentos populares e revolucionariamente organizados. A lei passou a ser entendida como mandamento, desvinculada dos pactos e das promessas. Isso foi uma brecha, em clara contradição com o processo de secularização, para a ação excepcional, supraconstitucional por parte dos governantes. Esse poder excepcional disfarçou, mas tornou real a herança absolutista, pré-moderna entre nós. Dessa forma, a limitação do poder às leis construídas politicamente pôde ser superada a partir de dentro, do interior das próprias constituições. Recolocava-se assim uma prática que não condizia com o espírito revolucionário e o fazia malograr.

Essa atitude coincide com a ascendência das massas na política. Os grandes números, a ideia de maioria, de opinião pública dão um verniz democrático à política moderna e funcionam como sucedâneo do espírito revolucionário. A entrada da multidão na política está intimamente ligada à hegemonia da questão social na política. Com a entrada da multidão, a política cede seu espaço à sociedade e aos interesses dos grupos poderosos que, travestidos de opinião pública, passam a substituir a opinião política. Manipula-se, dessa forma, a participação popular organizada, deliberada; e a população é usada como torrente natural, guiada por sentimentos, palavras de ordens ou impressões que fazem do povo uma verdadeira manada. Talvez por essa razão, em momento algum, Arendt reivindica a democracia. Há um pressuposto de naturalização da população na democracia que Arendt não concorda. Arendt diferencia princípio da maioria do poder da maioria. Concorda com o primeiro, mas abomina o segundo. A maioria como princípio significa que a liberdade, o respeito e a dignidade estão ao alcance de todos os membros da comunidade e que o governo baseia-se na participação efetiva dos cidadãos. Por outro lado, significa, também, um instituto utilizado por todos os governos, em todas as suas formas, pois é inerente a qualquer tomada de decisão (Cf. ARENDT, 2011, p. 214-215). Já o poder da maioria significa que o governo tem um respaldo mudo, proveniente das massas desorganizadas, captado através de estatística ou da "opinião pública". Sobre isso, diz Arendt: "apenas quando a maioria, depois de tomar a decisão, passa a liquidar politicamente - e, em casos extremos, fisicamente - a minoria adversária, é que o mecanismo técnico da decisão da maioria degenera em governo da maioria" (Cf. ARENDT, 2011, p. 215).

Essa relação clássica entre a democracia e a massificação, presente, de certa forma, já em Aristóteles, faz nossa autora se distanciar da 
democracia e das suas instituições modernas, e preferir, em termos de formas de governo, uma combinação entre a democracia popular direta com a tradição republicana. Essa combinação reúne e mantém a capacidade de agir, falar e deliberar com a ideia de lei, objetividade institucional e divisão dos poderes. Dessa forma, os espaços formais tornam-se espaços garantidores da aparição dos cidadãos e a liberdade é mantida como participação. Ao contrário da democracia de massa que tende à unidade, à soberania, ao interesse único ou dos grandes conglomerados econômicos, Arendt tende à pluralidade institucional e política. De norte a sul, de leste a oeste, a hegemonia das democracias de massa significou o abandono da busca da liberdade pública ("pursuit of freedom") em prol da busca da felicidade ("pursuit of happiness"). O vigor da democracia de massa é prépolítico (nação, multidão). Isso implicou a conversão dos cidadãos em indivíduos massificados, solitários, impotentes e do Estado em fiador do progresso econômico sem fim. Segundo Arendt, "essas reivindicações violentas de felicidade [...] infelizmente não pode ser preenchida por nenhuma ação política." (ARENDT, 2011, p. 305). Ela desintegrou as nascentes institucionalizações da liberdade, mesmo nos Estados Unidos. A compreensão da felicidade como algo privado, relacionada ao bem-estar pessoal e à abundância constitui a especificidade do sonho e da ideologia americana. (Cf. ARENDT, 2011, p. 172-173). Essa visão e direção prática corroeram o impulso revolucionário que relacionava liberdade e igualdade à ação. Conquistou-se o bem-estar, mas perdeu-se a liberdade de agir, importância maior da revolução. A ação tornou-se monopólio de poucos, a indiferença e a letargia em relação às coisas públicas generalizaram-se.

A esses aspectos e entraves, soma-se a questão da representação. Arendt não é contra a representação. Toda política implica em representação. Nossa autora não é rousseauista, não defende uma transparência absoluta. Isso implicaria um retorno ao estado de natureza que Arendt discorda. A política implica em laços e vínculos que dão sustentação e inclui o homem numa rede que o torna cidadão, pertencente a uma comunidade politicamente organizada, uma persona. Essa rede sustenta e dá sentido à sua vida biológica que sem essa sustentação fica desamparada, vulnerável. O problema de Arendt é com o sistema de partido. O sistema de representação partidário está na raiz de muitos problemas da política moderna. Sua hegemonia foi traçada no interior dos movimentos e das vanguardas revolucionárias, como uma forma de apressar a realização da necessidade histórica e o progresso social, além de reproduzir o próprio poder nos movimentos. Mas, com isso, o élan revolucionário foi perdido. Segundo Arendt, "um povo representado é um povo escravo" (ARENDT, 2011, p. 304), pois ressurge a elitização do poder. Uma nova elite, desta feita emanada do povo, vai suceder as elites pré-modernas forjadas no sangue, no berço e na riqueza. A maioria da população vai ficar de fora da política; põe-se, assim, por terra a ideia de igualdade. Dessa forma, a ação 
política tornou-se coisa de dirigentes profissionais, o poder foi monopolizado, o governo foi centralizado. A liberdade e a igualdade tornaram-se meras formalidades jurídicas. Um dos maiores problemas da substituição da ação pela representação foi a queda na dignidade da política. O governo tendeu a compreender a si mesmo apenas no diapasão administrativo e as decisões, como coisa de especialistas. Poder e economia transmutaram-se. Além da indiferença política e da massificação social, essa transformação fez da corrupção, do tráfego de influência, do lobby marcas endógenas do poder. Segundo Arendt, representa-se interesses, não pessoas e suas opiniões. A íntima ligação entre partido político, interesse e economia está na raiz da queda do espírito público e do vínculo republicano da ação política no mundo moderno. Há, destarte, uma igualação por baixo e uma elitização por cima. A multidão é igual na sua nudez e na sua impotência enquanto a elite impõe-se e domina os espaços estatais.

Para concluir, podemos dizer que os ventos libertários provocados pelo espírito revolucionários imaginado por Arendt volta e meia reaparecem para reanimar a política. Esse espírito prometeu muito com as revoluções, mas não conseguiu se estabelecer institucionalmente como espaço de aparição da liberdade e da igualdade, pois foi travado pela questão social, pela escravidão, pelo titubeio na aceitação da suficiência da legitimação política e secular, pela transformação da massificação social em massificação política e pela forma moderna da representação. Talvez por isso, os antigos problemas retornaram agora em escala planetária: doenças, corrupção, isolamento, violência, fome, crime organizado e indiferença. Isso não significa a prevalência de uma natureza má ou pecaminosa, mas a fragilidade dos humanos que vagueiam desamparados nos desertos da opulência e do consumo, da inovação científica e tecnológica e dos governos poderosos. Diante dessa realidade, primaveras aparecem e, como escreveu Arendt, os homens, como quer que sejam em sua singularidade, são capazes de se unir numa comunidade que, "embora composta de "pecadores", não precisa refletir necesariamente esse lado "pecaminoso" da natureza humana”. (ARENDT, 2011, p. 227). 


\section{Referências bibliográficas}

AGAMBEN, Giorgio. Homo Sacer: o poder soberano e a vida nua I. Tradução de Henrique Burigo. Belo Horizonte: editora UFMG, 2002.

ARENDT, Hannah. Sobre a Revolução. Trad. de Denise Bottmann. São Paulo: Companhia das Letras, 2011. . On Revolution. Londres: Peguin Books, 1990.

La tradition cachée - Le Juif comme paria. Paris: Christian Bourgois, 1987. . Auschwitz et Jérusalem. Paris: Deux temps,1991.

ARENDT, Hannah. Origens do Totalitarismo. Trad. de Roberto Raposo. São Paulo, Companhia das Letras, 1990b.

. Karl Marx and the Tradition of Western Political Thought. IN:

Social Research, Nova York, V. 69, Nº2, 2002, p. 273-319.

. Entre o passado e o futuro. Trad. de Mauro Barbosa de Almeida.

São Paulo: Perspectiva, 2000.

ARENDT, Hannah et JASPERS, Karl. Correspondence (1926-1969). Trad. de Robert e Rita Kimber. New York: HB\&C, 1992.

BERNSTEIN, Richard. Hannah Arendt and the Jewish Question. Cambridge, The MIT Press, 1996.

DUARTE, André. As revoluções modernas entre o passado e o futuro: a repetição transfigurada da origem. IN: O pensamento à sombra da ruptura. São Paulo: Paz e Terra, p. 266-318.

- Hannah Arendt e o pensamento político: a arte de distinguir e relacionar conceitos. Argumentos - Revista de Filosofia da UFC, Fortaleza, $\mathrm{N}^{\mathrm{o}}$ 09, 2013, p. 39-62.

ENEGRÉN, André. Révolution et Fondation. IN: La pensée Politique de Hannah Arendt. Paris: PUF, 1984, p.173-190.

HABERMAS. J. Die Geschichte von den Zwei Revolutionen, Merkur, 1966, no 218, p. 479-482.

MARX, Karl. A questão Judaica. Tradução de Nélio Schneider e Wanda Brant. Campinas: Boitempo, 2010.

PANCERA, Carlo G. K. Arendt e Maquiavel: fundação, violência e poder no pensamento republicano. IN: Argumentos, No 09, 2013, p. 140-153.

QUINTANA, Laura. ¿Cómo prolongar el acontecimiento? acción e institución en Hannah Arendt. IN: Argumentos, nº 09, 2013, p. 120-139.

RIBEIRO, Renato Janine. História e soberania (de Hobbes à Revolução). IN: A última razão do reis. São Paulo: Companhia das Letras, 1993. p. 197119. 